\title{
ON THE INVESTIGATION OF WHEEL FLANGE CLIMB DERAILMENT MECHANISM AND METHODS TO CONTROL IT
}

\author{
Habibollah Molatefi, Amin Mazraeh \\ School of Railway Engineering, Iran University of Science And Technology, Tehran, Iran \\ e-mail:molatef@iust.ac.ir; amin.mazraeh.me@gmail.com
}

\begin{abstract}
In this research, investigations are focused on the study of railway vehicle wheel flange climb derailment. A three dimensional nonlinear dynamic model of the wheel-set and suspension system is developed. Having validated the model through field tests, the effect of friction coefficient, wheel-set AOA, vehicle suspension system and running speed on the wheel flange climb derailment are investigated. In addition, different rail lubrication methods are studied and their effects on the wheel flange climb derailment are compared in the case of two point contact for nonlinear wheel-rail profiles. The results are debated and recommendations proposed to improve running safety against derailment.
\end{abstract}

Keywords: modified Nadal criterion, wheel flange climb derailment, wheel-rail angle of attack, rail lubrication

\section{Introduction}

Due to ever growing demand especially for an increase in running speed and keeping up with required running safety regulations, investigation on the derailment phenomenon and its mechanism have been of interest. More and more researches are done to find parameters affecting this phenomenon, particularly the wheel flange climb derailment. Parameters influencing the wheel flange climb derailment are often related to wheel-rail interaction geometry, dynamic and tribo features according to available literature. To address the demand for running safety, efforts were devoted to develop formulas that predict running safety criterion for wheel on an outer rail at curves. A very famous one was the work published by Nadal which was developed later by numerous researchers (Iwnicki, 2006). In the 19th century he developed a relation between wheel-rail geometry properties and friction coefficient to predict the maximum ratio of wheel lateral to vertical forces $(L / V)$ at which the wheel flange climb derailment occurs. He assumed that in this condition, forces acting on the outer wheel are in equilibrium, hence the problem was considered as a two dimensional problem with quasi-static presumption. The formula depends on the coefficient of friction and the rail side-wheel flange contact angle.

Figures 1a to 1d show the wheel-set angle of attack (AOA) for different cases in addition to the wheel-rail experiencing two point contact. With respect to Nadal's formula, the wheel-set AOA is not considered. That is why the effects of this parameter on the wheel flange climb derailment with quasi static presumption are ignored just the same as the effect of the other wheel on the inner rail at curves.

Regarding to Nadal limit as shown in Fig. 2, field tests showed different limit values for derailment when the wheel-set AOA was considered. The difference is highlighted when the wheel-set AOA contains negative values or does not have considerable positive values. Therefore, improved Nadal theories have been introduced to present a better insight into the wheel-set derailment criterion.

Reviewing the available literature, there have been efforts to study the effects of wheel-rail geometry and dynamic features on the wheel flange climb derailment and, hence, mathematical 

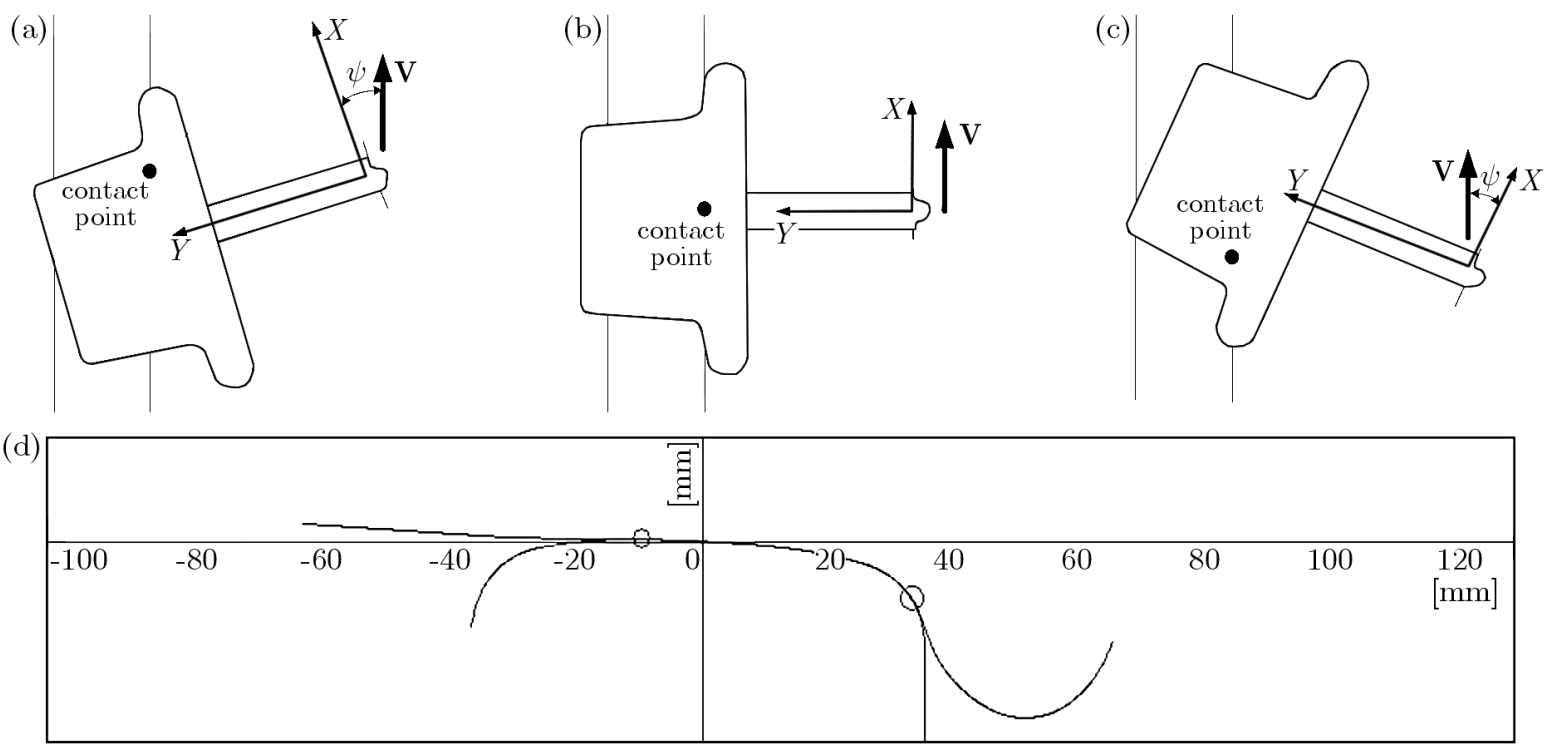

Fig. 1. Wheel-set AOA in rail-wheel flange contact (Santamaria et al., 2009) in addition to demonstration of the wheel-rail two point contact; (a) positive wheel-set angle of attack, (b) zero angle of attack, (c) negative angle of attack, (d) wheel-rail two point contact

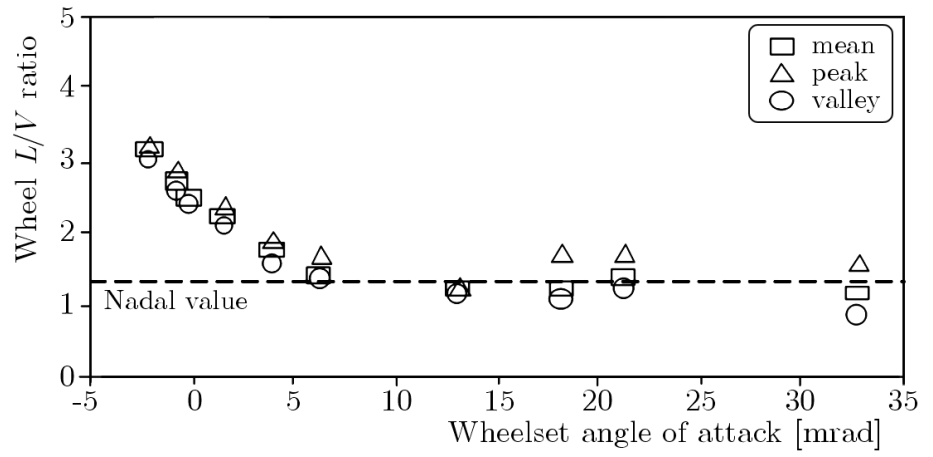

Fig. 2. Results of the wheel lateral to vertical forces ratio by field tests (Shust et al., 1997)

relations have been developed. Yokose $(1965,1966)$ investigated the effect of wheel-set AOA on the wheel flange climb derailment. He suggested a mathematical model in which the lateral creep force is derived as a function of the friction coefficient, wheel-set AOA and wheel flange angle. Weinstock (1984) suggested a formula in which the effects of both wheels (the term friction coefficient of the inner rail was added up to Nadal equation) of wheel-set on the wheel flange climb derailment were considered. TCRP (TCRP report 71, 2005) performed investigations to determine the parameters which affect the wheel flange climb derailment as well. Moreover, Elkins and $\mathrm{Wu}(2000)$ also studied efficient parameters in the wheel derailment mechanism in addition to introduction of new derailment criteria.

More recently, studies have been devoted to the development of mathematical models validated through field tests with the aid of commercial software or developed codes. Wilson et al. (2011) compared and investigated different methods of safety against derailment and debated some issues on validation of derailment simulations. Also some researches were conducted by Brabie and Andersson (2007), Yamashita and Sugiyama (2012) on simulation and study methodology of wheel derailment.

A method suggested, in which the wheel-rail interaction can be improved especially in curves in aspect of derailment, was the proposal for wheel-rail lubrication which has been investigated by some researchers (Heavy haul conference, 2001; Eadie et al., 2002). Also some investigations 
on the effects of lower rail lubrication in improving running safety were performed by Ishida et al. (2008). They investigated the effects of lubrication on the traction coefficient and change in lateral forces exerted on the wheel-set in aspect of derailment safety in curves.

Many lubrication methods (friction management which can lead to change in slip-friction coefficient diagram) have been proposed and utilized in various railway networks. Those common methods include outer rail side lubrication, outer rail side-rail head lubrication, in addition to the inner rail head and rail side lubrication. Iran railway network is currently using the outer-rail side lubrication method with unknown efficiency with regard to practical service conditions and numerous derailments in curves and turnouts which have been reported (reports are confidential). Also the wheel-rail interaction for Iran railway network is exposed to two point contact due to using S1002 and UIC60 standards for the wheel-rail profile with rail inclination 1:20. In this case, not so considerable research works have been done.

Considering the scientific research studies which have been done to examine the wheel flange climb derailment, further investigations are necessary to be performed in order to understand the derailment mechanism and increase rolling stock transportation safety. Thus it is the purpose of this research to develop a model validated through field tests to study the effects of parameters affecting the wheel flange climb derailment. In this research, the effects of wheel-set AOA and the wheel-rail coefficient of friction on the wheel flange climb derailment are studied. In addition, a study on an appropriate wheel-rail contact algorithm is done. In the case of achieving an improvement in the wheel-rail interaction in curves and considering various lubrication methods currently in use in railway networks, it is necessary to compare the efficiency of various lubrication methods in railway operation and choose the appropriate one. The large number of parameters included in the wheel-rail tribo system in aspect of lubrication, affect the friction coefficient. Therefore, in this research, the effects of change in the friction coefficient on running safety are investigated for both rails.

\section{Modeling}

In the first step, it is required to find a proper wheel-rail contact algorithm among those suggested and currently in use. Indeed, those algorithms should be compared to field tests as shown in Fig. 2 to determine the appropriate method to be used in the wheel-rail contact problem investigation.

A single 5 degree of freedom wheel-set with a frame is modeled in Universal Mechanism software on elastic rails (Euler beams on foundation) which are shown in Fig. 3a,b. The frame contains longitudinal, vertical, lateral, yaw and roll degrees of freedom. The roll movement of the frame is considered in the case the effect of the other wheel in the wheel-set in addition to different lubrication methods are investigated in curve. During the simulations, the frame is laterally displaced $(0.002 \mathrm{~m} / \mathrm{s}$ to $0.008 \mathrm{~m} / \mathrm{s})$. Lateral displacement of the wheel-set at such speeds will not result in applying impulsive loads to the wheel. Simulations are performed on a straight track. A constant wheel-set AOA is applied to the wheel-set for investigation on the wheel flange climb derailment criterion as a function of the wheel-set AOA (control parameter).
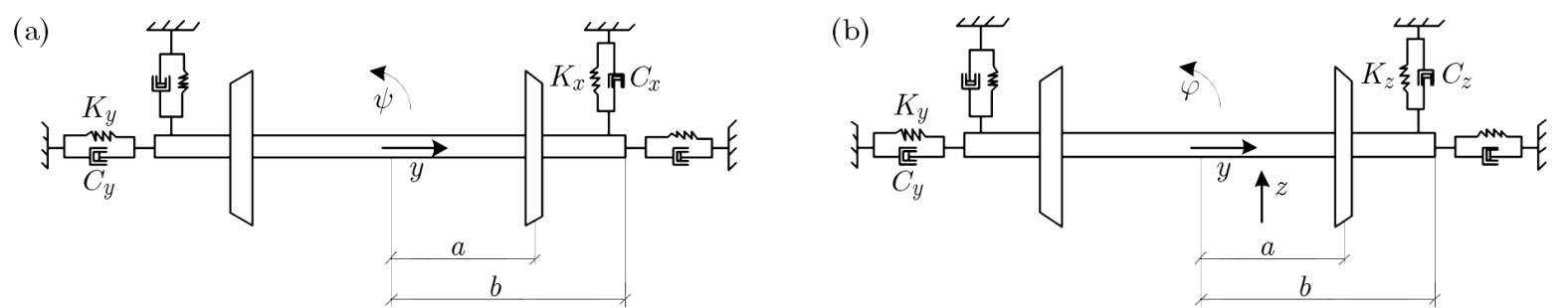

Fig. 3. Single wheel-set model with the frame and illustration of the suspension system; (a) top view, (b) front view 
The wheel-rail contact algorithms studied in this research include FastSim, FastSim A, Muller, Minov, non elliptic and simplified. The $L / V$ ratio (maximum value at which derailment occurs) is gained as a function of the wheel-set AOA. the results are presented for rail inclinations $0.05 \mathrm{rad}(1: 20)$ and $0.025 \mathrm{rad}(1: 40)$ with the track gauge of $1435 \mathrm{~mm}$. the rails are considered elastic with constant and continuous lateral stiffness of $18 \mathrm{E}+06 \mathrm{~N} / \mathrm{m}$, vertical stiffness $44 \mathrm{E}+06 \mathrm{~N} / \mathrm{m}$ with lateral damping of $1 \mathrm{E}+05 \mathrm{~N} \cdot \mathrm{s} / \mathrm{m}$ and vertical damping of $4 \mathrm{E}+05 \mathrm{~N} \cdot \mathrm{s} / \mathrm{m}$. the rail surfaces are considered even. In addition, the information about the S1002 wheel profile rolling radius difference (RRD) and contact points distribution on UIC60 rail profile considering both rail inclinations is shown in Fig. 4a and $4 \mathrm{~b}$ in addition to Fig. 5a and 5b. These diagrams show the nonlinear relation between wheel-set lateral displacement and wheel rolling radius in addition to wheel-rail contact points. The information of loads on the wheel-set, wheel-set mass and the suspension system is given in Table 1 . The bushing elements including rotational and torsion damping and stiffness on both wheel ends are not shown in Fig. 3 for simplicity.
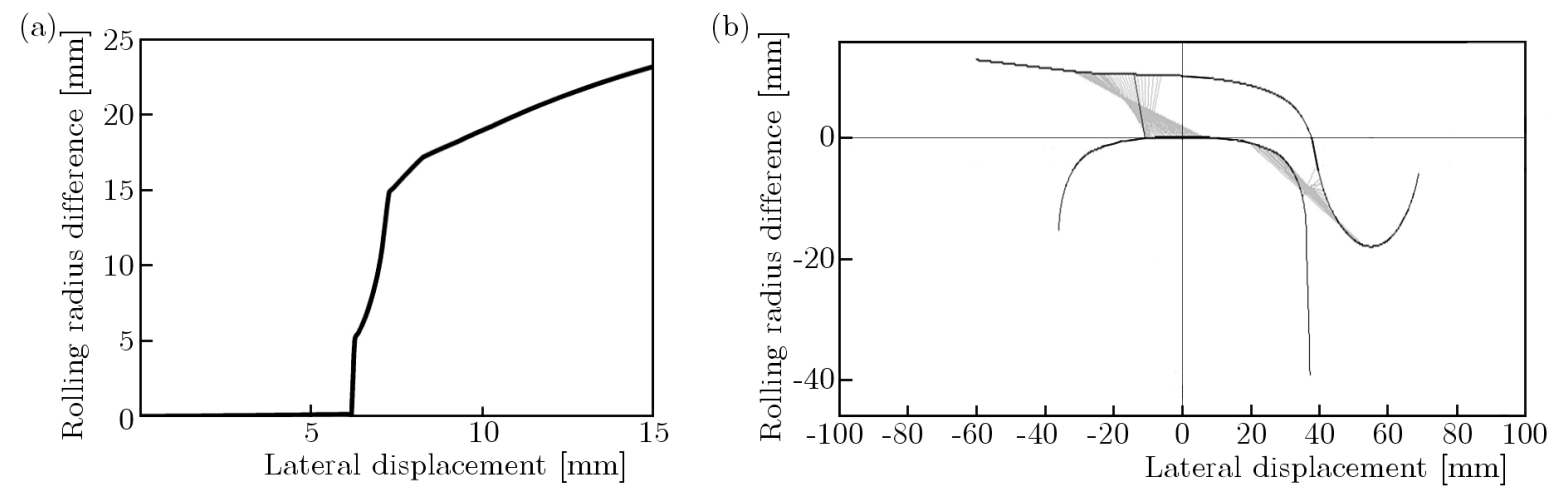

Fig. 4. Wheel-rail contact points and wheel-set rolling radius difference with rail inclination $0.05 \mathrm{rad}(1: 20)$; (a) wheel rolling radius difference (RRD), (b) wheel-rail contact points distribution
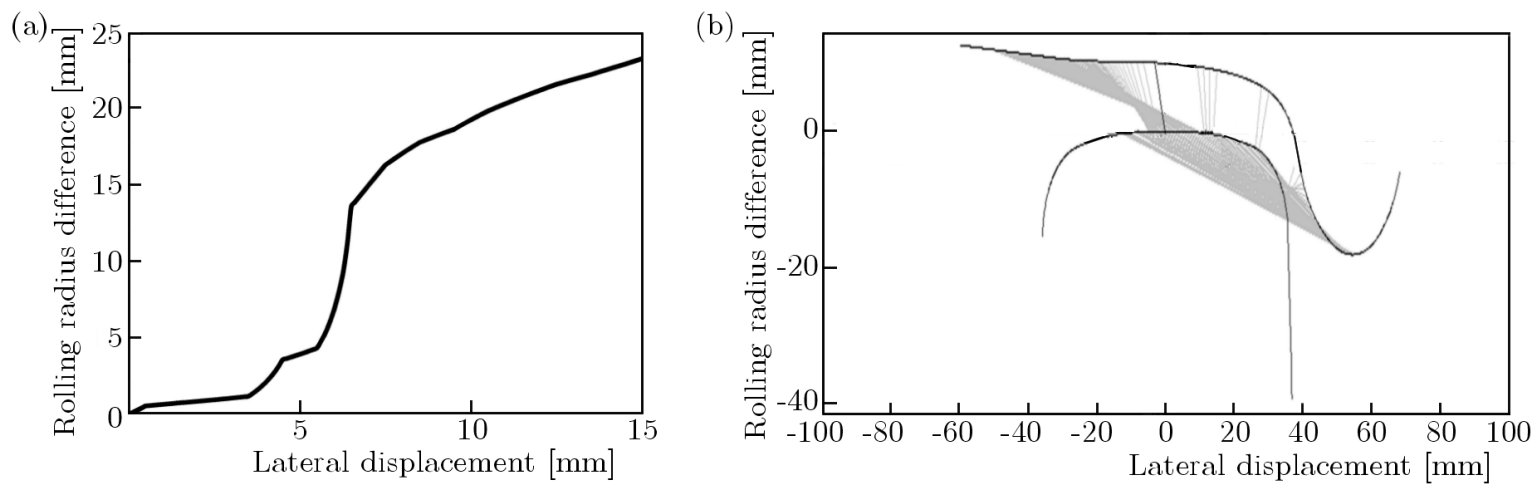

Fig. 5. Wheel-rail contact points and wheel-set rolling radius difference with rail inclination $0.025 \mathrm{rad}(1: 40)$; (a) wheel rolling radius difference $(\mathrm{RRD}),(\mathrm{b})$ wheel-rail contact points distribution

Also in the case of investigation on the efficiency of various lubrication methods with the wheel-rail two point contact in curves, the rail lubrication efficiency assessment in this research is conducted for the inner rail head and outer rail head-rail side lubrication. The effect of lubrication in curves for the outer wheel in the case of one point contact has already been investigated by many researchers. Here, two different lubrication zones are considered for the rail. As it is shown in Fig. 6, the angles $\beta_{r}$ and $\beta_{s}$ which are measured with respect to the vertical axis are used to determine the transition zone boundaries. The distance between the two angles is equal to 
Table 1. Wheel-set and suspension system parameters

\begin{tabular}{|l|c|l|c|}
\hline \multicolumn{1}{|c|}{ Parameter } & Value & \multicolumn{1}{c|}{ Parameter } & Value \\
\hline \hline Wheel-set mass & $1500 \mathrm{~kg}$ & Longitudinal stiffness & $2 \mathrm{E}+05 \mathrm{~N} / \mathrm{m}$ \\
\hline$M_{x}$ & $1200 \mathrm{~m}^{4}$ & Lateral stiffness & $1 \mathrm{E}+07 \mathrm{~N} / \mathrm{m}$ \\
\hline$M_{y}$ & $300 \mathrm{~m}^{4}$ & Vertical stiffness & $5 \mathrm{E}+04 \mathrm{~N} / \mathrm{m}$ \\
\hline$M_{z}$ & $1200 \mathrm{~m}^{4}$ & Wheel tape circle distance & $1500 \mathrm{~mm}$ \\
\hline Vertical damping & $4.5 \mathrm{E}+04 \mathrm{~N} \cdot \mathrm{s} / \mathrm{m}$ & Lateral damping & $2 \mathrm{E}+04 \mathrm{~N} \cdot \mathrm{s} / \mathrm{m}$ \\
\hline
\end{tabular}

$M_{k}$ - moment of inertia about $k$ axis, $k=x, y, z$

the transition zone between one friction zone to another. The friction coefficient variation in the transition zone is considered to be linear. The friction coefficient at the right and left side of the transition zones is constant with known values.

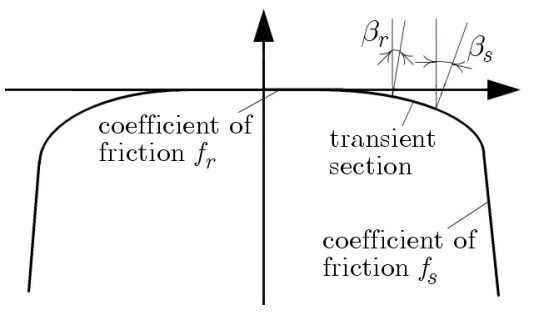

Fig. 6. A schematic view of the rail with three different friction coefficient zones (UM software, User manuals)

As has been mentioned before, the investigations are performed on straight tracks while the lab tests are often performed on rollers. In order to perform simulations, some aspects of the research are necessary to be considered. Firstly, a significant change in gravitational stiffness of the wheel-set is inevitable. This happens to be since the wheel-roller contact surface normal vector may not be parallel to the vertical axis. Secondly, as a result of the use of rollers, considering general normal (Hertz theory) and tangential wheel-rail contact algorithms, a change in creep forces during wheel-roller interaction is inevitable (Iwnicki, 2006). For more information about the effect of rollers on wheel-rail contact forces and dynamic behavior of the wheel-set in curves (especially wheel-set gravitational stiffness) the papers by Iwnicki (2006), Yaschinski (1990), De Pater (1993), Dukkipati (2000) are recommended. Thus in order to gain more realistic results and avoid dealing with the mentioned problems, investigations are performed on a straight path.

\section{Results}

The maximum $L / V$ value is shown in Fig. 7 which demonstrates a gradual increase in the lateral force to the maximum amount. Then, as the wheel flange climbs the rail, a sudden decrease in the $L / V$ ratio is observed. Moreover, from Fig. 7 it is seen that as the wheel flange climbs the rail, the wheel flange will move on the rail head surface for a while before derailment occurs. In addition, the RMS method is used for the case where there is perturbation in values at the top of the diagram as shown in Fig. 7.

The maximum $L / V$ ratios for different contact algorithms as a function of the wheel-set AOA are shown in Fig. 8 and Fig. 9 for different rail inclinations. Comparing the results from simulations to test results, the FastSim algorithm is appropriate to be used for numerical simulation. Also, comparing the results from different rail inclinations, it is concluded that for the rail inclination 1:40, the maximum $L / V$ values will be larger compared to the case with rail 


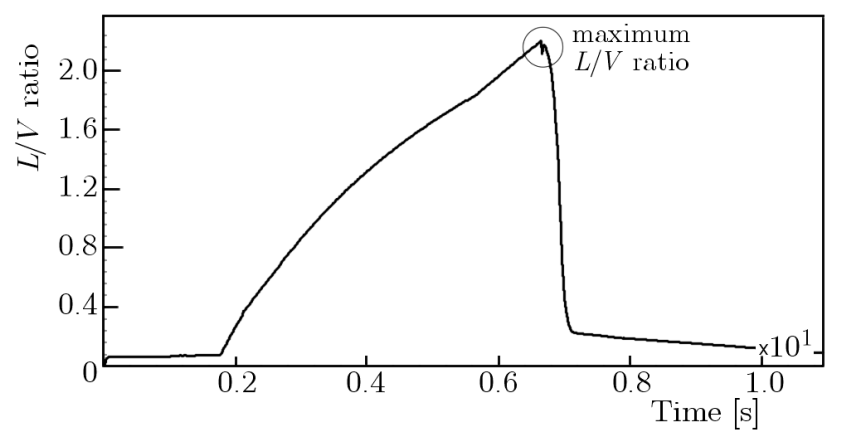

Fig. 7. Diagram of the $L / V$ forces ratio

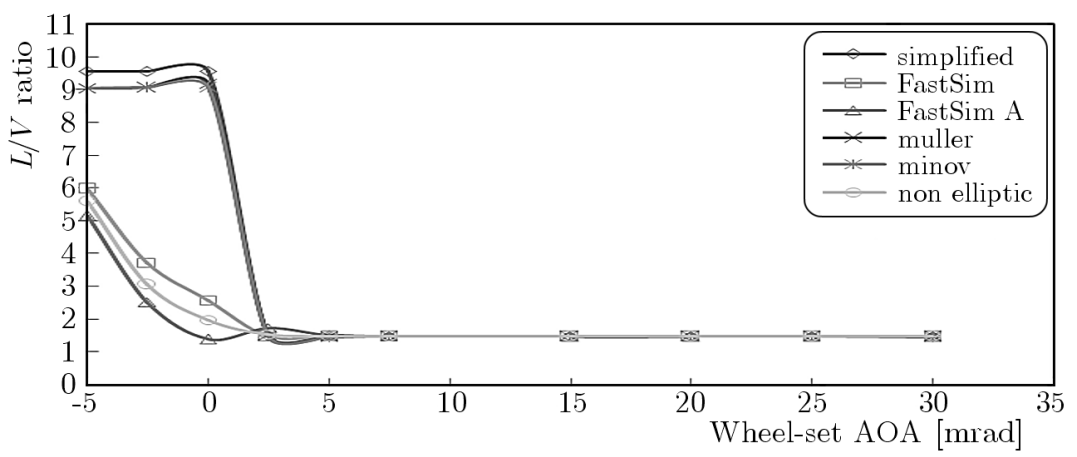

Fig. 8. Comparison between wheel-rail contact theories with rail inclination 1:20

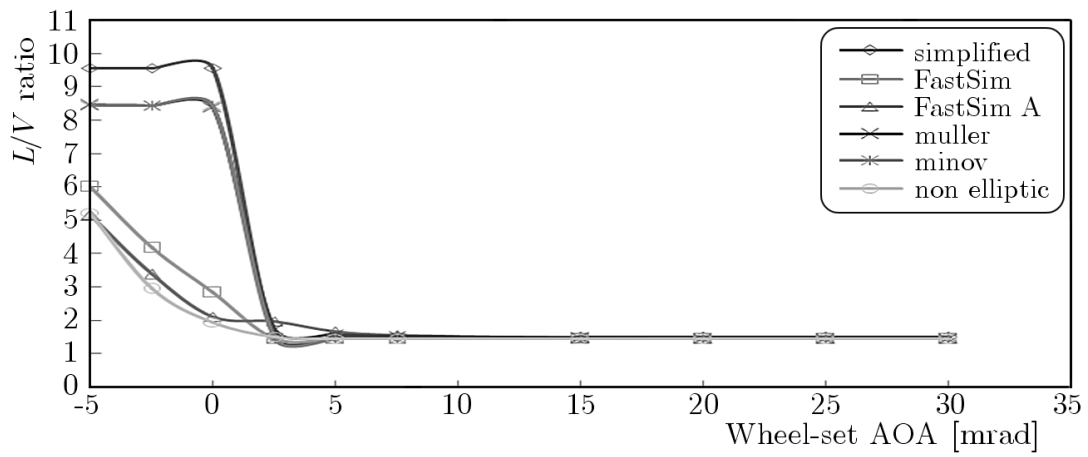

Fig. 9. Comparison between wheel-rail contact theories with rail inclination 1:40

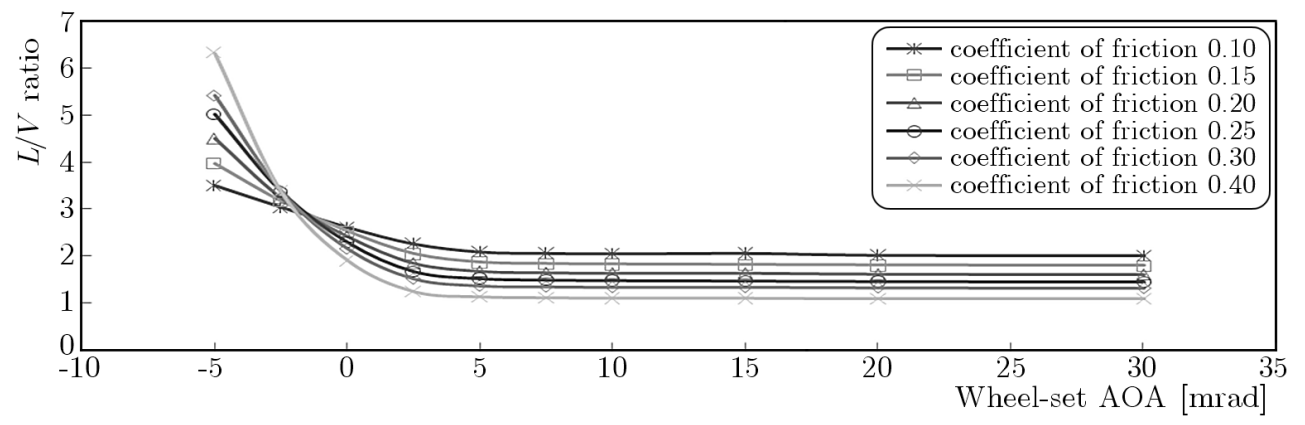

Fig. 10. $L / V$ values as a function of the coefficient of friction with rail inclination 1:20

inclination 1:20. Then the effects of the outer rail coefficient of friction on derailment considering different angles of attack are studied. No lubrication for the outer rail has been considered, thus the rail side and rail head friction coefficient values are similar. The results are shown in Fig. 10 and Fig. 11 for rail inclinations 1:20 and 1:40 using FastSim algorithm. 


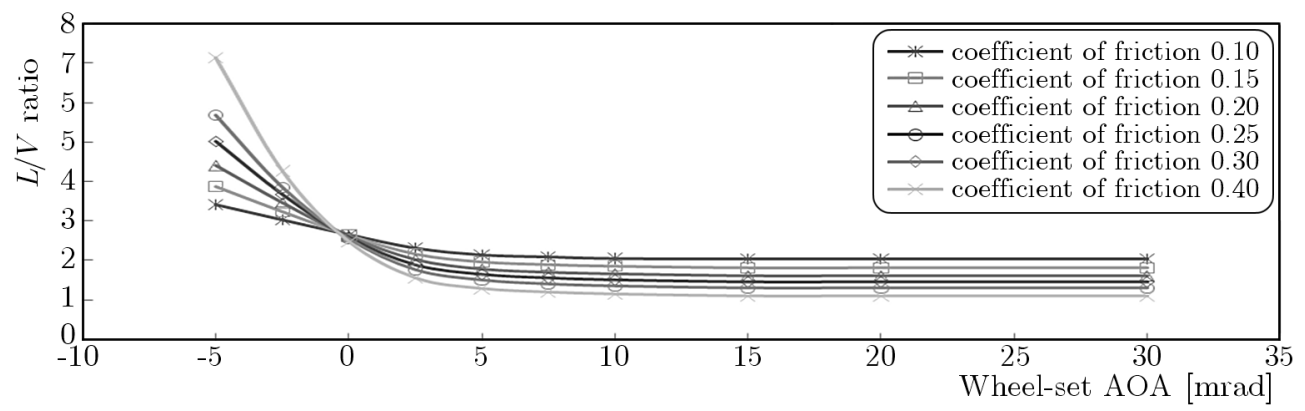

Fig. 11. $L / V$ values as a function of the coefficient of friction with rail inclination 1:40

With regard to the results for the positive wheel-set AOA, as the coefficient of friction increases, the wheel $L / V$ criteria would decrease. But the $L / V$ limit diagram after $10 \mathrm{mrad}$ will converge to a constant value for each coefficient of friction diagram. In the negative wheel-set AOA, as the coefficient of friction increases, the wheel $L / V$ values criterion would increase. It is seen that the friction coefficient has different influence on the wheel flange climb derailment criterion at positive and negative wheel-set AOAs, and the diagrams would cross each other approximately at the zero angle of attack. This means that in such a case near the zero wheelset AOA, the friction coefficient variation will not have considerable effect on the $L / V$ ratio. The effect of the friction coefficient on the maximum $L / V$ ratio at both positive and negative wheel-set AOAs is different, which is related to the direction and magnitude of creep forces.

Also the effect of lateral stiffness (vehicle primary suspension system) on the wheel $L / V$ ratio as a function of the wheel-set AOA has been investigated as shown in Fig. 12. The coefficient of friction and rail inclination are considered to be 0.28 and $1: 20$, respectively. It is seen that $L / V$ values are not very sensitive to the lateral suspension system. The differences are highlighted at the negative wheel-set AOA. Therefore, it is concluded that in the case of the wheel flange climb derailment, the suspension system affects the wheel flange climb criterion by making a change to the wheel-set yaw angle (or AOA). This means that in the lab tests, the exact suspension system, particularly the lateral one, would not be necessary to be used for the wheel flange climb derailment investigation where the wheel-set AOA is controlled.

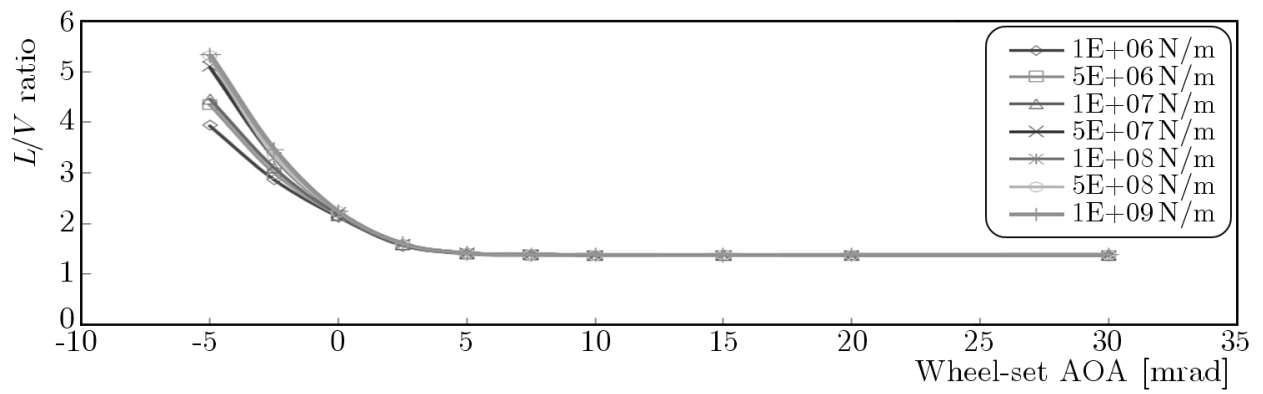

Fig. 12. $L / V$ values as a function of the suspension system lateral stiffness

Next, the effects of vehicle running speed on the $L / V$ ratio are studied. The simulations are performed for rail inclination 1:20 on the condition that the lateral stiffness and coefficient of friction would be constant. According to the results shown in Fig. 13, the running speed does not affect $L / V$ values considering an even rail surface. This means that for lab test applications, the operational running speed is not necessary to be applied to the wheel-set in the case of wheel flange climb derailment investigations.

In the next step, the effects of lubrication methods on wheel-rail interaction in curves are studied. The results for the inner and outer rails are shown in Tables 2 and 3. Friction coefficient values vary from 0.1 to 0.4 which have been reported from field measurements and tests per- 


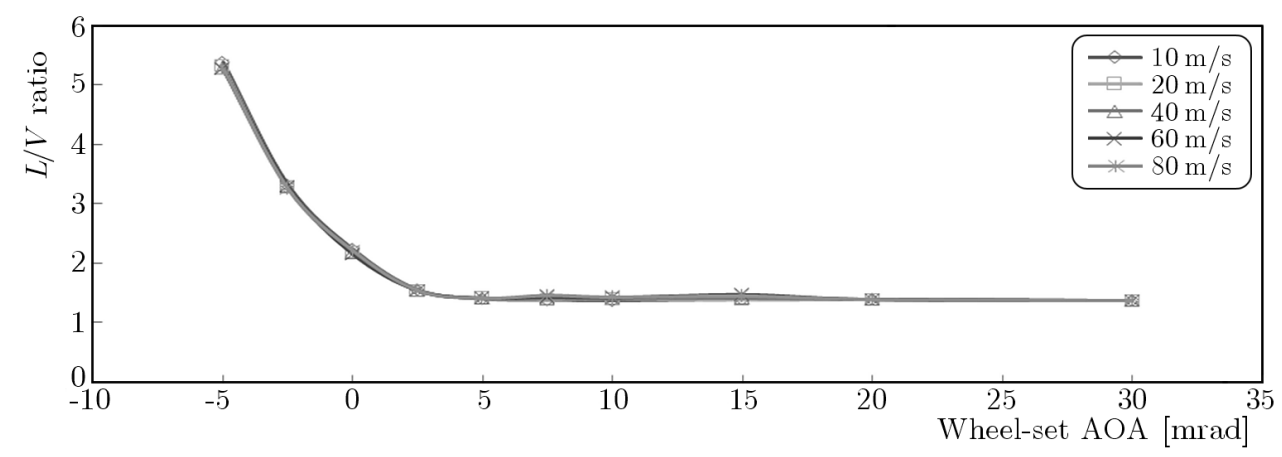

Fig. 13. $L / V$ values as a function of the dynamic system running velocity

formed in labs (Lewis and Olofsson, 2009). Simulations were performed for a curve with radius of $300 \mathrm{~m}$ and super elevation of $130 \mathrm{~mm}$ with constant running speed of $16 \mathrm{~m} / \mathrm{s}$. For the case of investigations on the effects of the outer rail head lubrication on running safety, the outer rail side and inner rail head friction coefficient was 0.3. Also for the case of inner rail head lubrication, the outer rail friction coefficient was 0.3 . It is be noted that due to rail inclination of 1:20 during the wheel-set curving, two point contact exists between the outer wheel and the rail.

Table 2. $L / V$ values for the outer rail as a function of the inner rail friction coefficient

\begin{tabular}{|c|c|}
\hline Friction coefficient & $L / V$ value \\
\hline \hline 0.20 & 0.22 \\
\hline 0.25 & 0.28 \\
\hline 0.30 & 0.33 \\
\hline 0.35 & 0.37 \\
\hline 0.40 & 0.41 \\
\hline
\end{tabular}

Table 3. $L / V$ values for the outer rail as a function of the outer rail-head friction coefficient

\begin{tabular}{|c|c|c|}
\hline Friction coefficient & $L / V$ value & AOA $[\mathrm{mrad}]$ \\
\hline \hline 0.10 & 0.26 & 2.4 \\
\hline 0.15 & 0.26 & 2.6 \\
\hline 0.20 & 0.28 & 3.2 \\
\hline 0.25 & 0.30 & 3.9 \\
\hline 0.30 & 0.33 & 4.6 \\
\hline 0.35 & 0.38 & 5.2 \\
\hline 0.40 & 0.40 & 5.5 \\
\hline
\end{tabular}

The results show that decreasing the inner rail head friction coefficient by means of lubrication will improve vehicle safety at curves. It is shown that the wheel-rail two point contact will decrease the wheel-set steer ability since the resultant creep force for both points do not lie in the same direction, and even they can be in opposite direction (TCRP report 71, 2005). Therefore, in order to decrease the second contact point influence on the wheel-set steer ability, the outer rail head friction modification has been investigated. The results show that as the friction coefficient for the outer rail head increases, the risk of derailment would increase. In addition, decreasing the friction coefficient results in an increase in running safety. In order to monitor the wheel-set curving performance in much more detail, the wheel-set AOA has been monitored as well. As shown in Table 3, decreasing the outer rail head friction coefficient will decrease the wheel-set AOA. This will result in a better wheel-set steer ability in curves. Moreover, it 
is seen that the inner rail lubrication has better effect in comparison with the outer rail head lubrication.

The important point in lubrication of the outer rail is that the high difference (rail head friction coefficient is much larger than the rail side friction coefficient) between the flange and wheel tread friction coefficient (while wheel flange lubrication is interested for the wheel-rail wear purposes) will increase the risk of derailment, which can be seen in Table 3 .

\section{Conclusions}

In this investigation, effects of the friction coefficient, wheel-set AOA, rail lubrication, lateral suspension and longitudinal velocity on the wheel flange climb derailment are studied in order to have a better insight into the derailment mechanism and parameters which affect this phenomenon. Thus, a model has been developed and validated by field test results. The main results are presented as follows:

- As the wheel-set AOA sign changes from positive to negative values, the friction coefficient would have different effects on the maximum $L / V$ ratio. Moreover, it is shown that as the wheel-set AOA reaches the zero value, the friction coefficient approximately loses its effect on the maximum $L / V$.

- It is shown that the wheel-set running velocity and primary suspension system (in the case the wheel-set AOA is controlled) would not have a noticeable effect on the maximum $L / V$. Thus, conducting further research on wheel flange climb derailments at labs, it is not necessary to apply the exact primary suspension and running speed.

- Derailment would not take place right after the wheel flange climb. The wheel flange will continue moving on the rail head surface for a while. This will give a better insight, particularly in cases where investigations on derailed trains are of interest. In the cases where the wheel flange climb is the main cause of the derailment, it is very likely to see the trace of the wheel flange on the rail head surface at the derailment area.

- It is shown that by means of the inner rail head lubrication, the vehicle safety would improve. In addition, the outer rail head lubrication in the case of two point contact will enhance safety of the vehicle. But the inner rail head lubrication has a better effect on the wheel-set safety. Moreover, it has been found that a high friction coefficient difference between the outer rail side and rail head will increase the risk of derailment. Therefore, this must be considered while the outer rail lubrication at curves is of interest.

- Conducting research on the effects of the outer rail head lubrication on safety revealed that in the case of two point contact, a considerable decrease in the wheel-set AOA and, as a result, an improvement in the safety margin is possible.

For current railway conditions with two point contact for the outer wheel-rail in curve, in the case of improving safety against derailment, low rail lubrication is suggested. In addition, the method including simultaneous outer rail lubrication along with the inner rail lubrication is proposed. It must be considered that in the case of outer rail side lubrication, the outer rail head friction coefficient must be close to the rail side friction coefficient and moreover, traction obligations must be regarded as well.

\section{Acknowledgment}

This research was supported by Iran University of Science and Technology Center of Excellence. 


\section{References}

1. Brabie D., Andersson E., 2006, Dynamic simulation of derailments and its consequences, Journal of Vehicle System Dynamics, 44, 652-662

2. Dukkipati R.V., 2000, Vehicle Dynamics, Alpha Science International, Ltd.

3. De Pater A.D., 1993, The motion of a railway wheel-set supported by a pair of rollers as compared with the motion of such a wheel-set along a tangent track, Delft University of Technology, Laboratory for Engineering Mechanics, Report, 1012

4. Eadie D.T., Kalousek J., Chiddick K.C., 2002, The role of high positive friction (HPF) modifier in the control of short pitch corrugations and related phenomena, Journal of Wear, 253, 185-192

5. Elkins J., Wu H., 2000, New criteria for flange climb derailment, IEEE/ASME Joint Railroad Conference, Newark, NJ, April 4-6

6. International Heavy Haul Association, 2001, Guidelines to best practices for heavy haul railway operations: wheel and rail interface issues, 2808 Forest Hills Court Virginia Beach, Virginia 23454, USA

7. Ishida M., Ban T., Iida K., Ishida H., Aoki F., 2008 , Effect of moderating friction of wheel/rail interface on vehicle/track dynamic behavior, Journal of Wear, 265, 1497-1503

8. Iwnicki S., 2006, Handbook of Railway Vehicle Dynamics, CRC Press, Taylor \& Francis Group, LLC

9. Lewis R., Olofsson U., 2009, Wheel Rail Interface Handbook, CRC, Whodhead Publishing Limited, Abington Hall, Granta Park, Great Abington, Cambridge CB21 6AH, UK

10. Santamaria J., Vadillo E.G., Gomez J., 2009, Influence of creep forces on the risk of derailment of railway vehicles, Journal of Vehicle System Dynamics, 47, 721-752

11. Shust W.C., Elkins J.A., Kalay S., El-Sibaie M., 1997, Wheel-climb derailment tests using AAR's track loading vehicle, Association of American Railroads Report, R-910

12. TCRP Report 71 Vol. 5, 2005, Flange climb derailment criteria and wheel/rail profile management and maintenance guidelines for transit operations, track related research, transit cooperative research program

13. Weinstock H., 1984, Wheel climb derailment criteria for evaluation of rail vehicle safety, Proceedings of ASME Winter Annual Meeting, 84-WA/RT-1, New Orleans, LA

14. Wilson N., Fries R., Haigermoser A., Mrang M., Evans J., Orlava A., 2011, Assessment of safety against derailment using simulations and vehicle acceptance tests: a worldwide comparison of state-of-the-art assessment methods, Journal of Vehicle System Dynamics, 49, 1113-1157

15. Yamashita S., Sugiyama H., 2012, Numerical procedure for dynamic simulation of two-point contact wheel-rail contact and flange climb derailment of railroad vehicles, Journal of Computational and Nonlinear Dynamics, 7, 1012-1019

16. Yaschinski A., 1990, On the application of similarity laws to a scaled railway bogie model, $\mathrm{PhD}$ Thesis, TU Delft University

17. Yokose K., 1965, On the theory (sic) of derailment of one-axle wheel (in Japanese), Railway Technical Research Report, $\mathbf{5 0 4}$

18. Yokose K., 1966, A theory of the derailment of wheel-set, Quarterly Report RTRI, 7, 3 